\title{
Recurrent Glioblastoma
}

National Cancer Institute

\section{Source}

National Cancer Institute. Recurrent Glioblastoma. NCI Thesaurus. Code C126306.

The reemergence of glioblastoma after a period of remission. 